\title{
Longitudinal study of living kidney donor glomerular dynamics after nephrectomy
}

\author{
Colin R. Lenihan, ${ }^{1}$ Stephan Busque, ${ }^{2}$ Geraldine Derby, ${ }^{1}$ Kristina Blouch, ${ }^{1}$ Bryan D. Myers, ${ }^{1}$ and Jane C. Tan ${ }^{1}$ \\ 'Division of Nephrology, Department of Medicine and 'Department of Surgery, Stanford University School of Medicine, Palo Alto, California, USA.
}

BACKGROUND. Over 5,000 living kidney donor nephrectomies are performed annually in the US. While the physiological changes that occur early after nephrectomy are well documented, less is known about the long-term glomerular dynamics in living donors.

\begin{abstract}
METHODS. We enrolled 21 adult living kidney donors to undergo detailed long-term clinical, physiological, and radiological evaluation pre-, early post- (median, 0.8 years), and late post- (median, 6.3 years) donation. A morphometric analysis of glomeruli obtained during nephrectomy was performed in 19 subjects.

RESULTS. Donors showed parallel increases in single-kidney renal plasma flow (RPF), renocortical volume, and glomerular filtration rate (GFR) early after the procedure, and these changes were sustained through to the late post-donation period. We used mathematical modeling to estimate the glomerular ultrafiltration coefficient $\left(\mathrm{K}_{\mathrm{f}}\right)$, which also increased early and then remained constant through the late post-donation study. Assuming that the filtration surface area (and hence, $K_{f}$ ) increased in proportion to renocortical volume after donation, we calculated that the $40 \%$ elevation in the single-kidney GFR observed after donation could be attributed exclusively to an increase in the $K_{f^{\prime}}$. The prevalence of hypertension in donors increased from $14 \%$ in the early post-donation period to $57 \%$ in the late post-donation period. No subjects exhibited elevated levels of albuminuria.
\end{abstract}

CONCLUSIONS. Adaptive hyperfiltration after donor nephrectomy is attributable to hyperperfusion and hypertrophy of the remaining glomeruli. Our findings point away from the development of glomerular hypertension following kidney donation.

TRIAL REGISTRATION. Not applicable.

FUNDING. NIH (R01DK064697 and K23DK087937); Astellas Pharma US; the John M. Sobrato Foundation; the Satellite Extramural Grant Foundation; and the American Society of Nephrology.

\section{Introduction}

The prevalence of living kidney donation has expanded substantially since the first donor nephrectomy was performed in 1954 (1). Almost one-third of the 16,487 kidney transplants performed in 2012 in the US were from living donors. Understandably, there has been much attention paid to the safety of living kidney donation. Older reports of long-term donor follow-up suggest that there is no excess risk of end-stage renal disease (ESRD) or death compared with that in the general population $(2,3)$. However, more recent studies indicate that living kidney donors are at higher risk of ESRD, cardiovascular disease, and mortality when compared with stringently matched healthy controls $(4,5)$.

Immediately following nephrectomy, an approximately $40 \%$ increase in renal plasma flow (RPF) and glomerular filtration rate (GFR) in the remaining kidney ensues $(6,7)$. This is associated with glomerular hypertrophy, which may contribute to the adap-

\section{Related Commentary: p. 972}

Conflict of interest: The authors have declared that no conflict of interest exists Submitted: September 8, 2014; Accepted: December 11, 2014.

Reference information: / Clin Invest. 2015;125(3):1311-1318. doi:10.1172/JCI78885 tive hyperfiltration by enhancing the filtration surface area and hence the whole-kidney ultrafiltration coefficient $\left(\mathrm{K}_{\mathrm{f}}\right)(7)$. Another hypothetical contribution to hyperfiltration is an increase in glomerular capillary - and hence ultrafiltration - pressure. Such glomerular hypertension could result in glomerular injury and impaired renal function in the long term. However, surprisingly little is known about the long-term effects of nephrectomy on glomerular filtration dynamics or glomerular number in otherwise healthy humans. We therefore enrolled 21 adult living donors to undergo morphometric analysis of glomeruli obtained during surgery as well as serial clinical, physiological, and radiological evaluation before and after kidney donation.

\section{Results}

Response to donor nephrectomy in healthy humans. Twenty-one subjects underwent clinical, physiological, and radiological assessments immediately before, early after (median, 0.8 years), and late after (median, 6.1 years) (hereafter, pre-donation, early post-donation, and late post-donation) living kidney donation. A morphometric evaluation of glomeruli was performed on renocortical tissue that was obtained by wedge biopsy at the time of donor nephrectomy in 19 subjects. Baseline demographic, physio- 


\section{Table 1. Baseline demographic, physiologic, and morphometric characteristics of the study subjects}

\begin{tabular}{|c|c|}
\hline Baseline characteristics & \\
\hline Subjects $(n)$ & 21 \\
\hline Age at kidney donation (yr) & $54.8 \pm 6.5$ \\
\hline Female sex $(\%)$ & 45 \\
\hline MAP (mmHg) & $96 \pm 12$ \\
\hline Hypertension (\%) & 14 \\
\hline Hypertensive medication use (\%) & 10 \\
\hline Serum creatinine (mg/dl) & $0.94 \pm 0.19$ \\
\hline$\pi_{A}(\mathrm{mmHg})$ & $26.5(25.5-28)$ \\
\hline Pre-donation GFR (ml/min/1.73 m²) & $92(82-102)$ \\
\hline Pre-donation RPF (ml/min/1.73 m²) & $435(405-543)$ \\
\hline Clomerular volume $\left(\mu m^{3} \times 10^{6}\right)^{A}$ & $2.71 \pm 0.83$ \\
\hline Hydraulic permeability $\left(\mathrm{m} / \mathrm{s} \text { per } \mathrm{Pa} \times 10^{-9}\right)^{\mathrm{A}}$ & $2.64 \pm 0.29$ \\
\hline $\mathrm{SNK}_{\mathrm{f}}[\mathrm{nl} /(\mathrm{min} \times \mathrm{mmHg})]^{\mathrm{A}}$ & $9.37 \pm 3.02$ \\
\hline Early follow-up (yr) & $0.8(0.5-1.1)$ \\
\hline Late follow-up (yr) & $6.3(5.2-7.6)$ \\
\hline
\end{tabular}

logic, and morphometric characteristics are summarized in Table 1. Sixteen subjects were ethnically of mixed European descent, and 5 were Asian. Figure 1 depicts serial physiological, laboratory, and radiological measurements performed pre-, early post-, and late post-donation. The single-kidney GFR increased significantly $(P<0.001)$ from that seen pre-donation to early post-donation and remained stable thereafter, averaging 47, 64, and $66 \mathrm{ml} / \mathrm{min} /$ $1.73 \mathrm{~m}^{2}$ pre-, early post-, and late post-donation, respectively. The corresponding values for single-kidney RPF changed in parallel with the GFR; 235,314 , and $335 \mathrm{ml} / \mathrm{min} / 1.73 \mathrm{~m}^{2}$ pre-, early post-, and late post-donation, respectively $(P<0.001)$. A similar pattern of increase was observed for renocortical volume: 103, 131, and $139 \mathrm{~cm}^{3}$ pre-, early post-, and late post-donation, respectively $(P<0.001)$. An increasing fraction of the patients became hypertensive during follow-up and received antihypertensive medications. However, measured mean arterial pressure (MAP) remained constant throughout the study. Serum creatinine rose early post-donation and remained stable thereafter. Plasma oncotic pressure $\left(\pi_{\mathrm{A}}\right)$ remained unchanged from the pre-donation to early post-donation periods $(26.5 \mathrm{mmHg}$ [25.5-28 $\mathrm{mmHg}$ ] versus 26.9 $\mathrm{mmHg}$ [26-27.8 $\mathrm{mmHg}$; $P=0.74)$. We lacked the equipment to measure the $\pi_{\mathrm{A}}$ during the late post-donation study. However, serum albumin levels remained unchanged from pre-donation $(3.95 \pm 0.26 \mathrm{~g} / \mathrm{dl})$ to early post-donation $(3.97 \pm 0.21 \mathrm{~g} / \mathrm{dl})$ to late post-donation $(3.94 \pm 0.18)$ periods, providing indirect evidence for the constancy of $\pi_{\mathrm{A}}$ during the late post-donation period.

We next assessed whether post-donation hyperfiltration was associated with changes in $\mathrm{K}_{\mathrm{f}}$. We used Deen's mathematical model $(8,9)$ to estimate the single-kidney $\mathrm{K}_{\mathrm{f}}$ longitudinally. Since the MAP was similar at all 3 study time points, we first calculated the $\mathrm{K}_{\mathrm{f}}$, assuming that the glomerular transcapillary hydraulic pressure gradient $(\Delta \mathrm{P})$ was fixed at $40 \mathrm{mmHg}$ (Figure $2 \mathrm{~A})$. The $\mathrm{K}_{\mathrm{f}}$ increased from a median pretransplantation level of $4.9 \mathrm{ml} /(\mathrm{min}$ $\times \mathrm{mmHg})$ to $7.1 \mathrm{ml} /(\mathrm{min} \times \mathrm{mmHg})$ at the early post-donation point $(P<0.01$ versus pre-donation $)$ and to $7.0 \mathrm{ml} /(\mathrm{min} \times \mathrm{mmHg})$ late post-donation $(P<0.01$ versus pre-donation). To allow for the possibility of glomerular hypertension in hypertensive subjects (despite normalization of their blood pressure with treatment), we performed an additional analysis using a $\Delta \mathrm{P}$ of $40 \mathrm{mmHg}$, in which the subject was normotensive, and $43 \mathrm{mmHg}$ at any time point after the subject became hypertensive. This too revealed an early increase in the $\mathrm{K}_{\mathrm{f}}$ that was maintained through the late post-donation period (Figure 2B). Sensitivity analyses restricted to (a) the 13 subjects never exposed to an angiotensin-converting enzyme inhibitor (ACEI) or angiotensin receptor blocker (ARB) and (b) the 11 subjects never exposed to any antihypertensive drug (Figure 2C) yielded similar results.

We also considered the (unlikely) possibility that post-donation hyperfiltration was maintained exclusively by glomerular hypertension. We therefore estimated $\Delta \mathrm{P}$ pre-, early post-, and late post-donation, assuming that the $\mathrm{K}_{\mathrm{f}}$ remained fixed at the predonation levels (Figure 2D) and that the pre-donation $\Delta \mathrm{P}$ was 40 $\mathrm{mmHg}$. We found a similar pattern of an early rise in the postdonation $\Delta \mathrm{P}$ that was sustained through the late post-donation period Furthermore, in order to highlight the inverse relationship between the $\mathrm{K}_{\mathrm{f}}$ and $\Delta \mathrm{P}$, we modeled the late post-donation $\mathrm{K}_{\mathrm{f}}$ using progressively higher $\Delta \mathrm{P}$ values and found that $\Delta \mathrm{P}$ values of 45 and $50 \mathrm{mmHg}$ would result in maintenance of the late post-donation GFR, despite $\mathrm{K}_{\mathrm{f}}$ decrements of $32 \%$ and $46 \%$, respectively.

$\mathrm{K}_{\mathrm{f}}$ is a product of the glomerular-filtering surface area and the hydraulic permeability of the glomerular capillary. Since the whole-kidney-filtering surface area is dependent on both glomerular number and glomerular volume, we hypothesized that measured renocortical volume would, in turn, reflect the whole-kidney $\mathrm{K}_{\mathrm{f}}$. In an analysis of the 20 subjects with pre-donation radiological data, we found a significant correlation (Spearman's $r=0.66[95 \%$ CI, 0.29-0.86]; $P=0.0016$ ) between the pre-donation renocortical volume and $\mathrm{K}_{\mathrm{f}}$ (Figure $3 \mathrm{~A}$ ).

As reported above, kidney donation was associated with an increase in renocortical volume (Figure 1C). Assuming proportionate glomerular hypertrophy, we used the percentage change in renocortical volume at early and late time points to compute the corresponding $\mathrm{K}_{\mathrm{f}}$ values. We then used the model to calculate the $\Delta \mathrm{P}$ required to maintain the GFR measured at early and late time points using these calculated values for the early post- and late post-donation $\mathrm{K}_{\mathrm{f}}$ (in which the initial $\Delta \mathrm{P}$ was set at $40 \mathrm{mmHg}$ for all subjects). Renocortical volume measurements were available at all study time points for 12 subjects; therefore, we applied either the mean change in renocortical volume to generate early and late $\mathrm{K}_{\mathrm{f}}$ values in all 21 subjects (Figure $3 \mathrm{~B}$ ) or individual changes in renocortical volume to generate the corresponding $\mathrm{K}_{\mathrm{f}}$ values in the 12 subjects with complete radiological follow-up. The computed $\Delta \mathrm{P}$ remained remarkably constant across the study time points; early and late $\Delta \mathrm{P}$ post-donation levels averaged $41 \pm 3.7 \mathrm{mmHg}$ and $40.5 \pm 2.2 \mathrm{mmHg}$, and $41.2 \pm 3.7 \mathrm{mmHg}$ and $40.5 \pm 2.0 \mathrm{mmHg}$ for all 21 subjects and for the 12 subjects with complete renocortical volume data, respectively.

Estimation of glomerular numbers. The single-nephron $\mathrm{K}_{\mathrm{f}}\left(\mathrm{SNK}_{\mathrm{f}}\right)$ was calculated in 19 subjects in whom glomerular volume, filtering surface density, and hydraulic permeability were measured in biopsy specimens obtained at the time of donation (9). Predonation glomerular morphometric data are shown in Table 1. We 

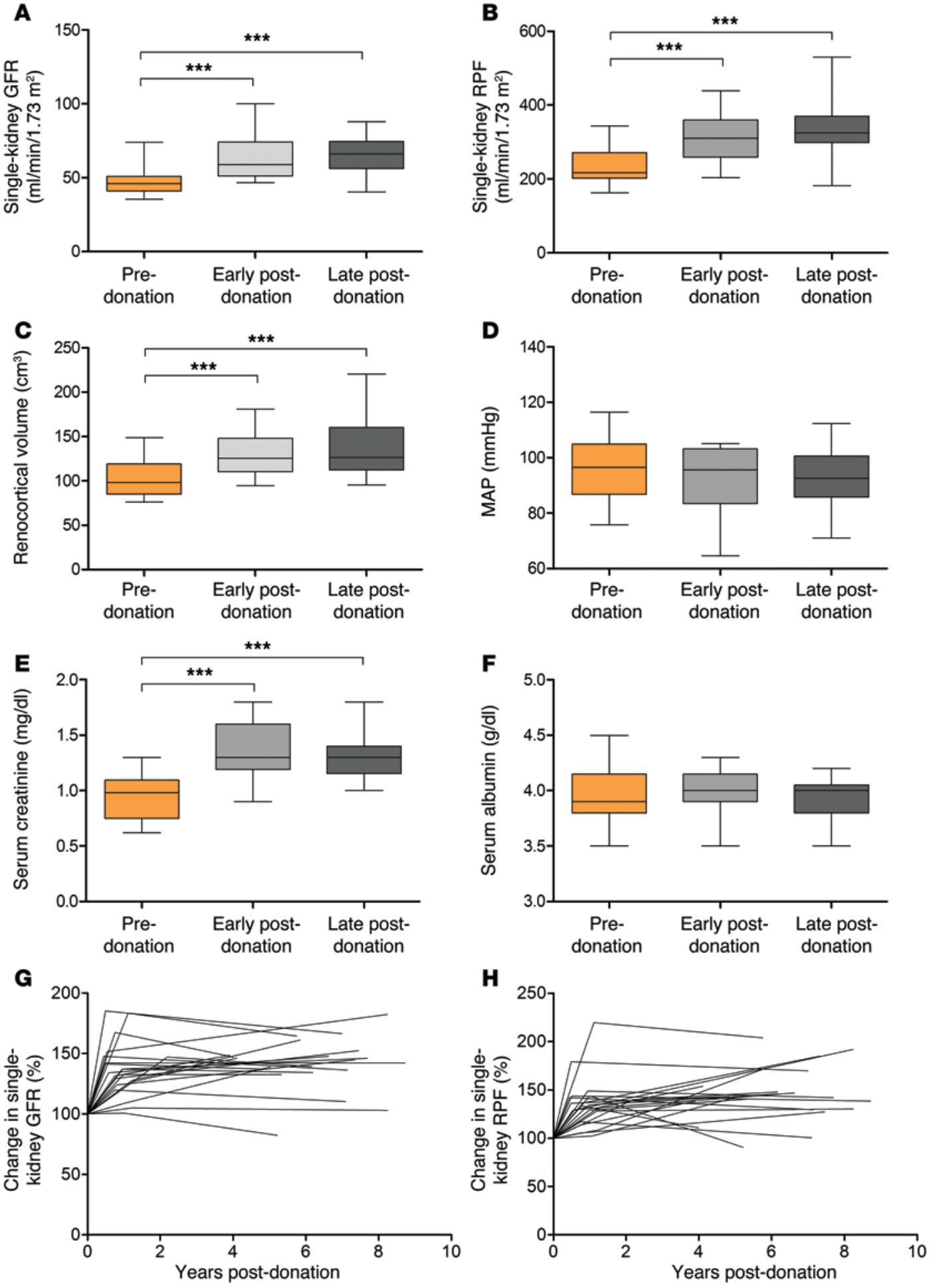

Figure 1. Baseline clinical, physiological, and radiological parameters.

(A) Single-kidney GFR measured pre-, early post-, and late post-kidney donation $(n=21)$. (B) Single kidney RPF measured pre-, early post-, and late post-kidney donation ( $n=21)$. (C) Renocortical volume measured pre-, early post-, and late post-kidney donation $(n=12)$. (D) MAP measured pre-, early post-, and late post-kidney donation $(n=21)$. (E) Serum creatinine measured pre-, early post-, and late post-kidney donation $(n=21)$. (F) Serum albumin measured pre-, early post-, and late post-kidney donation ( $n=21)$. (G) Percentage of single-kidney GFR change over time plotted separately for each individual $(n=21)$.

(H) Percentage of RPF change over time plotted separately for each individual $(n=21)$. Statistical comparisons made using repeated-measures ANOVA with Bonferroni's post-test (B-F) or Friedman's test with Dunn's post-test (A). ${ }^{* * *} P<0.001$. In each plot, the boxes extend between the first and third quartiles, the line within the boxes represents the median value, and lower and upper whiskers extend between the minimum and maximum values. divided the pre-donation whole-kidney $\mathrm{K}_{\mathrm{f}}$ (calculated with a $\Delta \mathrm{P}$ of $40 \mathrm{mmHg}$ ) by the measured $\mathrm{SNK}_{\mathrm{f}}$ to yield a pre-donation number of functioning glomeruli $\left(\mathrm{N}_{\mathrm{FG}}\right)$ estimate of 641,730 (range of 396,554 to 713,399$)$ per kidney.

We then computed the late post-donation $\mathrm{N}_{\mathrm{FG}}$, assuming that a maximal increase in $\mathrm{SNK}_{\mathrm{f}}$ had occurred by the early post-donation time point (an assumption that will tend to overestimate the late $\mathrm{N}_{\mathrm{FG}}$ ) and that the $\Delta \mathrm{P}$ was constant at $40 \mathrm{mmHg}$. This revealed a nonsignificant trend toward a modest decrease in the $\mathrm{N}_{\mathrm{FG}}$ to
538,946 (range of 364,194 to 709,175 ), at a median of 6.3 years after donation ( $P=0.38$, 2-tailed Wilcoxon matched-pairs test).

Hypertension and albuminuria. The prevalence of hypertension in subjects increased from 3 pre-donation to 4 and 12 early and late post-donation, respectively. The corresponding prevalence of antihypertensive medication use in subjects was 2, 3, and 10, respectively (Table 2). ACEIs and ARBs were the most commonly prescribed antihypertensive drug class. No subjects had micro- or macroalbuminuria at any of the study time points. 

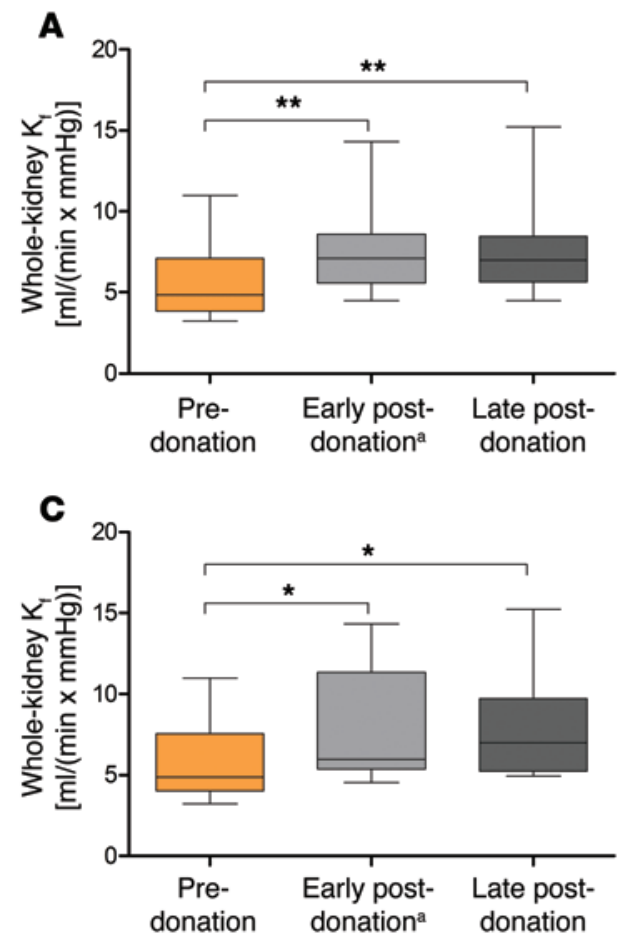

Figure 2. Glomerular dynamics before and after donor nephrectomy. (A) Whole-kidney $\mathrm{K}_{\mathrm{f}}$ values pre-, early post-, and late post-kidney donation, calculated assuming a fixed $\Delta \mathrm{P}$ of $40 \mathrm{mmHg}$ at all time points $(n=21)$. (B) Whole-kidney $\mathrm{K}_{\mathrm{f}}$ values pre-, early post-, and late post-kidney donation, calculated using $\Delta \mathrm{P}$ values of $40 \mathrm{mmHg}$ or $43 \mathrm{mmHg}$ for normotensive and hypertensive time points, respectively $(n=21)$. (C) Whole-kidney $\mathrm{K}_{\mathrm{f}}$ values pre- early post-, and late post-kidney donation, calculated assuming a fixed $\Delta \mathrm{P}$ of $40 \mathrm{mmHg}$ at all time points, in subjects unexposed to antihypertensive medications $(n=11)$. (D) $\Delta \mathrm{P}$ values pre-, early post-, and late post-kidney donation, calculated assuming a fixed whole-kidney $\mathrm{K}_{f}(n=21)$. Statistical comparisons were made using Friedman's test with Dunn's post-test. ${ }^{*} P<0.05$; ${ }^{* *} P<0.01$; ${ }^{* *} P<0.001$. In each plot, the boxes extend between the first and third quartiles, the line within the boxes represents the median value, and the lower and upper whiskers extend between the minimum and maximum values, excluding outliers. aln A, B, and C, a single outlier with a $\mathrm{K}_{\mathrm{f}}$ value of $34.6 \mathrm{ml} /(\mathrm{min} \times \mathrm{mmHg})$ early post-donation is not shown in the plots but is included in all statistical analyses.

The median and interquartile ranges for the urine albumin/creatinine ratio pre-, early post-, and late post-donation were not detectable (ND) (ND -15.6 mg/g), $1.8 \mathrm{mg} / \mathrm{g}(\mathrm{ND}-8.7 \mathrm{mg} / \mathrm{g})$, and $\mathrm{ND}$ (ND $-7 \mathrm{mg} / \mathrm{g})$, respectively.

\section{Discussion}

In this detailed longitudinal follow-up study of 21 middle-aged, living kidney donors, we found that adaptive hyperfiltration by the remaining kidney is maintained at a constant level for 6 to 8 years after donation. The hyperfiltration is sustained through an increase in RPF and in the whole-kidney $\mathrm{K}_{\mathrm{f}}$, with no clear-cut contribution from glomerular hypertension.

Concern about a less favorable outcome after contralateral nephrectomy stems from experiments using the 5/6 nephrectomized rat. In this model, nephron loss results in glomerular hypertension in the "remnant kidney," with subsequent development of hypertension, proteinuria, and glomerulosclerosis $(10,11)$. Two recent epidemiological studies have raised concern about the outcome of donors of a single kidney for transplantation. Both studies report that kidney donors have an increased relative risk of ESRD compared with that of matched healthy non-donors $(4,5)$. However, in the study by Mjøen et al., in which the etiology of ESRD was reported, segmental glomerulosclerosis was conspicuously absent as a cause of renal failure in prior kidney donors (4), suggesting that renal injury other than the remnant kidney phenomenon was responsible for the increased risk of failure of the remaining kidney.

The schematic diagram in Figure 4 illustrates that the magnitude of the GFR is dependent on RPF, glomerular ultrafiltration pressure $\left(\mathrm{P}_{\mathrm{UF}}\right)$, and the $\mathrm{K}_{\mathrm{f}}$. The single-nephron GFR is a product of $\mathrm{P}_{\mathrm{UF}}$ and the $\operatorname{SNK}_{\mathrm{f}}(12,13) . \mathrm{P}_{\mathrm{UF}}$ is determined by the opposing pressures across the glomerular capillary wall, where $\Delta \mathrm{P}$ is the difference between glomerular capillary hydraulic pressure and Bowman's space hydraulic pressure. An opposing pressure to that of $\Delta \mathrm{P}$ is exerted by glomerular capillary oncotic pressure, $\pi_{\mathrm{GC}}$, which increases along the course of the glomerular capillary as protein-free plasma is filtered, with an ensuing increase in glomerular capillary plasma protein concentration. The difference between $\Delta \mathrm{P}$ and $\pi_{\mathrm{GC}}$ at any given point along the glomerular capillary is the $\mathrm{P}_{\mathrm{UF}}$. In many studies of the Munich-Wistar rat, $\Delta \mathrm{P}$ and $\pi_{\mathrm{GC}}$ were observed to equalize before the end of the glomerular capillary, bringing filtration to a halt, a phenomenon referred to as filtration pressure equilibrium $(14,15)$. In humans, who are most likely in filtration pressure disequilibrium, the entire filtration surface area participates in filtration. Increased RPF increases the GFR through 2 mechanisms: (a) by diminishing the rate of increase in $\pi_{\mathrm{GC}}$ along the glomerular capillary, thereby increasing the $\mathrm{P}_{\mathrm{UF}}$ and GFR, and (b) in species that are in filtration pressure equilibrium, by shifting the point of equilibration downstream along the length of the capillary, thereby increasing the effective filtration surface area. The $\mathrm{K}_{\mathrm{f}}$ is a product of the filtration surface area and the hydraulic permeability of the glomerular barrier. Hydraulic permeability is determined by the fenestrated capillary endothelium, the glomerular basement membrane, and the filtration slits that separate the epithelial foot processes. In the absence of a change in the $\mathrm{P}_{\mathrm{UF}}$ or filtration surface area, any decline in the GFR must be a consequence of diminishing hydraulic permeability of the 3-layered glomerular capillary wall, thereby lowering the $\mathrm{K}_{\mathrm{f}}$ independently of the filtration surface area.

In the immediate wake of nephrectomy, RPF increases by approximately $40 \%$, resulting in a parallel rise in the GFR (6). In addition to a sustained increase in RPF, post-donation hyper- 
A

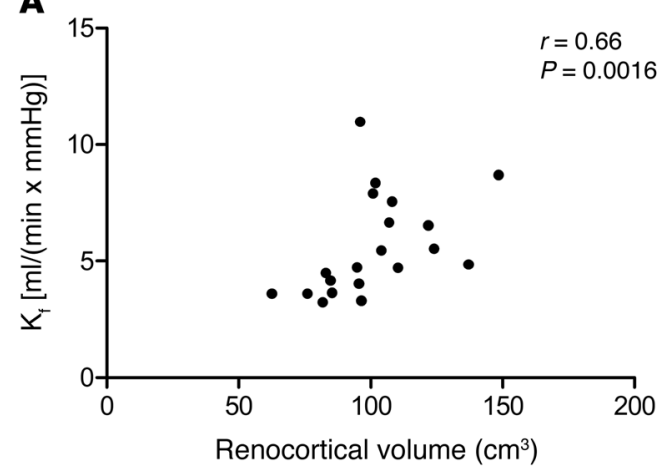

Figure 3. Relationship between renocortical volume and the $\mathrm{K}_{\mathrm{f}}$ and implications for post-donation glomerular dynamics. (A) Relationship between pre-donation renocortical volume and the $K_{f}$, assessed using Spearman's rank-order correlation $(n=20)$. (B) Estimated change in $\Delta P$, assuming that the $\mathrm{K}_{f}$ increases in proportion to the mean renocortical volume at each time point $(n=21)$. Statistical comparisons were made using Friedman's test with Dunn's post-test. In B, the boxes extend between the first and third quartiles, the line within the boxes represents the median value, and the lower and upper whiskers extend between the minimum and maximum values.

filtration may additionally be maintained by (a) compensatory glomerular hypertrophy, leading to an increase in the wholekidney $\mathrm{K}_{\mathrm{f}}$; (b) an increase in $\Delta \mathrm{P}$; or (c) some combination of both. Although the mechanism is contentious, glomerular hypertrophy is well described in both animal models, in which glomerular volume increases in proportion to the renocortical volume following uninephrectomy $(16,17)$, and in biopsies of solitary human functioning kidneys (18). Our subjects had a mean $27 \%$ and $33 \%$ increase in renocortical volume from the pre-donation to early and late post-donation periods, respectively. Indeed, when we modeled the whole-kidney $\mathrm{K}_{\mathrm{f}}$ based on the observed magnitude of renocortical hypertrophy, we found that the magnitude of post-donation hyperfiltration could be accounted for without the need to invoke an increase in $\Delta \mathrm{P}$.

We estimated glomerular numbers during the late post-donation period and observed a nonstatistically significant decrease in the $\mathrm{N}_{\mathrm{FG}}$ from the early post-donation level of 641,730 (range of 396,554 to 713,399 ) to 538,946 (range of 364,194 to 709,175 ). We speculate that the modest decline in glomerular number observed late post-donation reflects normal senescence in our middle-aged living donor population. Biopsy series suggest that glomerular obsolescence is unusual below the age of 40 years, but becomes increasingly prevalent after the age of 50 years $(19,20)$. We have previously demonstrated an inverse relationship between glomerular number and age in both living and deceased donor kidneys $(9,21)$. Human autopsy series have also shown a negative correlation between age and glomerular number $(22,23)$. The absence of post-donation albuminuria also points away from the remnant kidney syndrome and suggests that the modest decline in glomerular number reflects a benign form of senescence.

Finally, the prevalence of hypertension late post-donation approached $60 \%$. In the absence of a non-donor control population, the extent to which incident hypertension is attributable to kidney donation is difficult to judge. A retrospective study of over 1,200 living kidney donors, with a mean follow-up of 6.4 years, found that donors had a $40 \%$ increased risk (hazard ratio, 1.4; CI, 1.2-1.7) of being diagnosed with hypertension compared with that of non-donor controls (24). A recent study from the UK pooled 8 have contributed to the preservation of glomerular function and number observed over the 6- to 8-year follow-up period.

Our study represents, to our knowledge, the most detailed longitudinal physiological follow-up study of living kidney donors to date. However, our investigation does have certain limitations including its small size. Late post-donation evaluations were performed at a median of 6.3 years (interquartile range, 5.2-7.6 years), and it is possible that with longer follow-up, the effects of "relative glomerulopenia" might become evident. Since $\Delta \mathrm{P}$ cannot be measured directly, we assumed a level of 40

\section{Table 2. Antihypertensive medication use before and after kidney donation}

\begin{tabular}{|c|c|c|c|}
\hline Subject & Pre-donation & Early post-donation & Late post-donation \\
\hline 1 & - & - & Amlodipine/valsartan \\
\hline 2 & - & - & Valsartan \\
\hline 3 & Benazapril & Benazapril & HCTZ/lisinopril \\
\hline 4 & HCTZ/telmisartan & HCTZ/telmisartan & HCTZ/benazapril \\
\hline 5 & - & - & Lisinopril/doxasocin \\
\hline 6 & - & - & Lisinopril \\
\hline 7 & - & Lisinopril & Lisinopril \\
\hline 8 & - & - & Lisinopril \\
\hline 9 & - & - & - \\
\hline 10 & - & - & - \\
\hline 11 & - & - & - \\
\hline 12 & - & - & - \\
\hline 13 & - & - & - \\
\hline 14 & - & - & - \\
\hline 15 & - & - & - \\
\hline 16 & - & - & - \\
\hline 17 & - & - & - \\
\hline 18 & - & - & - \\
\hline 19 & - & - & Atenolol \\
\hline 20 & - & - & HCTZ \\
\hline 21 & - & - & - \\
\hline
\end{tabular}

HCTZ, hydrochlorothiazide. 


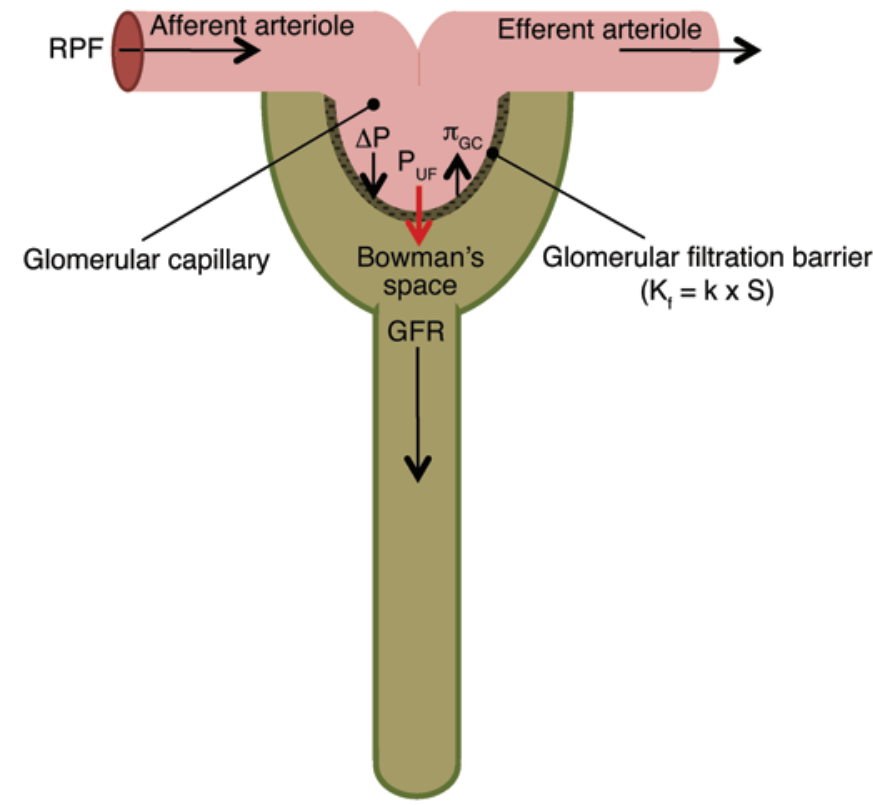

Figure 4. Schematic of glomerular filtration. The GFR is dependent on $R P F, P_{U F}$, and the $K_{f}$. At a given RPF, the single-nephron GFR is a product of the $\mathrm{P}_{\mathrm{UF}}$ and the $\mathrm{K}_{\mathrm{f}}\left(\mathrm{GFR}=\mathrm{P}_{\mathrm{UF}} \times \mathrm{K}_{\mathrm{f}}\right.$ ). The $\mathrm{P}_{\mathrm{UF}}$ is determined by Starling's forces across the glomerular capillary and is the difference between the $\Delta \mathrm{P}$ and the $\pi_{\mathrm{Cc}}\left(\mathrm{P}_{\mathrm{uF}}=\Delta \mathrm{P}-\pi_{\mathrm{cc}}\right)$. The amount of filtrate produced by a given pressure across the glomerular filtration barrier is described by the $K_{f}$, which is determined by its hydraulic permeability and surface area.

$\mathrm{mmHg}$ for all donors in our main analyses. This estimate for $\Delta \mathrm{P}$ assumes that humans are in a state of filtration pressure disequilibrium. Our assumption stems from (a) experimental studies in dogs demonstrating filtration pressure disequilibrium and (b) the relation between RPF and GFR observed during volume expansion in humans, suggestive of filtration pressure disequilibrium. Much of our current understanding about glomerular dynamics stems from physiological studies of the Munich-Wistar rat, in which superficial glomeruli permit glomerular micropuncture and direct glomerular capillary pressure measurement. In hydropenic conditions, these rats have been shown (by multiple investigators) to be in a state of filtration pressure equilibrium $(14,15)$. In these experiments, volume contraction and renal vasoconstriction resulting from the anesthetic and surgical procedures likely contributed to a diminution of RPF and a predisposition to filtration pressure equilibrium, although in volume-depleted animals, insight into the relation between RPF and filtration pressure equilibrium/disequilibrium is further confounded by a concurrent angiotensin II-mediated contraction of the $\mathrm{K}_{\mathrm{f}}(26)$. However, Munich-Wistar rats could be driven into filtration pressure disequilibrium with a volume expansion-induced increase in glomerular plasma flow (from 60 to $80 \mathrm{nl} / \mathrm{min}$ to $>150 \mathrm{nl} / \mathrm{min}$ ) (27). Certain colonies of Munich-Wistar rats were also observed to be in filtration pressure disequilibrium in hydropenic conditions, a consequence of colony-specific differences in the $\mathrm{K}_{\mathrm{f}}(28)$.

Glomerular capillary pressure has also been indirectly estimated in other species using the nephron stop-flow technique, the results of which have been shown to correlate well with direct glomerular pressure measurements in Munich-Wistar rats (15). Such estimates in dogs have fairly consistently revealed filtration pressure disequilibrium $(29,30)$. Dogs are closer to humans in terms glomerular surface area and single-nephron RPF.

The presence or absence of filtration pressure equilibrium can be indirectly determined from the relation between RPF and GFR. In states of equilibrium, an acute increase in RPF leads to a proportionate elevation of the GFR, with the filtration fraction remaining constant (27). By contrast, in disequilibrium, increases in RPF associated with acute volume expansion result in a smaller or absent increase in the GFR associated with a decrease in the filtration fraction (27). We have previously demonstrated an absence of parallel increases in the GFR and a declining filtration fraction, despite substantial increases in RPF during volume expansion in healthy humans, pointing to filtration pressure disequilibrium (31-33). Following uninephrectomy, by contrast, our healthy donors exhibited parallel increases in RPF and GFR, with constancy of the filtration fraction across our 3 time points of evaluation. We infer that in the presence of filtration pressure disequilibrium, the observed post-donation hyperfiltration results from a compensatory glomerular hypertrophy-induced increase in the $\mathrm{K}_{\mathrm{f}}$, along with the associated augmentation of RPF. Were humans in filtration pressure equilibrium, the post-donation hyperfiltration seen in our living donors could be accounted for solely by the observed increase in RPF, however, we consider this scenario extremely unlikely.

Blood pressure throughout the study was well controlled, making it unlikely that post-donation hypertension resulted in elevation of glomerular pressure. Furthermore, a sensitivity analysis using the $\Delta \mathrm{P}$ value of $43 \mathrm{mmHg}$ for any subject with a diagnosis of hypertension yielded results similar to those of our primary analysis. We also found that exclusion of subjects treated with either angiotensin blockade or any anti-hypertensive agent did not materially affect results (11). Finally, the lack of non-donor controls makes mechanistic inference about post-donation changes in blood pressure difficult.

In conclusion, we have shown that post-donation hyperfiltration by the remaining kidney is maintained stable by a combination of an increase in RPF and in the $\mathrm{K}_{\mathrm{f}}$ resulting from compensatory glomerular hypertrophy. Our modeling argues against the development of significant glomerular hypertension following donor nephrectomy.

\section{Methods}

Study population. We enrolled 21 adult subjects prior to their kidney donation procedure. All donors underwent a standard medical, social, and psychological pre-donation assessment. Exclusion criteria for donation included a BMI of greater than $35 \mathrm{~kg} / \mathrm{m}^{2}$, glucose intolerance or diabetes, a creatinine clearance of less than $80 \mathrm{ml} / \mathrm{min} / 1.73 \mathrm{~m}^{2}$, and proteinuria. Well-controlled hypertension in subjects older than 50 years was not considered a contraindication to kidney donation. Subjects underwent study evaluations at 3 time points: (a) pre-donation, (b) early post-donation, and (c) late post-donation. Nineteen of the 21 subjects underwent a kidney biopsy at the time of their nephrectomy.

Assessment of kidney function. Subjects underwent a detailed assessment of kidney function before, and on 2 occasions following, donation. GFR and RPF were measured using iothalamate and para-aminohippuric acid (PAH) urinary clearance tests, respectively. RPF was cal- 
culated by dividing PAH clearance by an extraction ratio of 0.9 (34). Plasma oncotic pressure $\left(\pi_{\mathrm{A}}\right)$ was measured using membrane osmometry at pre-donation and early post-donation time points (35). Oncotic pressure measurement was not available at the late post-donation assessment. Instead, we measured serum albumin serially. Given that serum albumin levels were unchanged at all the study time points, we assumed constancy of oncotic pressures across the study and used the mean value of pre- and early post-donation oncotic pressures as an estimate of late post-donation oncotic pressure. Blood pressure was measured with a Dinamap (GE Healthcare). The $\mathrm{K}_{\mathrm{f}}$ was calculated using a mathematical model described by Deen et al. $(8,9)$. This requires knowledge of the GFR, RPF, $\pi_{\mathrm{A}}$, and $\Delta \mathrm{P}$. We have estimated that the $\Delta \mathrm{P}$ in healthy human glomeruli approximates $40 \mathrm{mmHg}$. This estimate follows from the assumption that humans are in a state of filtration pressure disequilibrium. Filtration pressure disequilibrium is characterized by an excess of $\Delta$ P over the opposing oncotic pressure at the efferent end of the glomerular capillary network. From $\pi_{\mathrm{A}}$ and the filtration fraction, we estimate that the efferent oncotic pressure ranges between 30 and 35 mmHg in healthy humans $(21,31)$. From the latter value, assuming the presence of filtration pressure disequilibrium, we accordingly inferred that the $\Delta \mathrm{P}$ approximates $40 \mathrm{mmHg}$. A number of subjects were diagnosed with hypertension either before or after donation. Since a proportion of the elevated arterial pressure is likely to be transmitted into the glomerular capillaries in hypertensive subjects, we also performed an additional analysis using a higher $\Delta \mathrm{P}$ estimate of $43 \mathrm{mmHg}$ in these individuals $(36,37)$. We defined hypertension as a blood pressure in excess of $140 / 90 \mathrm{mmHg}$ or the established use of antihypertensive medication in subjects previously diagnosed as hypertensive.

Estimation of kidney volumes. Donors underwent either MR or CT renal angiography before and after kidney donation. Whole-kidney and cortical volumes were estimated using 3D imaging with CT or MRI according to the Cavalieri principle (38). We changed protocols from MRI to CT imaging during the study period because of a concern about nephrogenic systemic fibrosis following gadolinium administration (39). We found excellent concordance (within $7 \mathrm{~cm}^{3}$ ) between the 2 modalities for renocortical volume estimation, and therefore, measurements obtained from either MRI or CT were used interchangeably.

Structural evaluation of glomeruli. A cortical wedge biopsy from the donated kidney was obtained from 19 subjects prior to transplantation. Each biopsy core was subjected to detailed light and electron microscopic analysis, as described in detail by us previously (9). Briefly, the percentage of global glomerular sclerosis, the fractional interstitial area, and the glomerular volume $\left(\mathrm{V}_{\mathrm{G}}\right)$ were measured using light microscopy. The filtration surface density $\left(\mathrm{S}_{\mathrm{v}}\right)$ of the glomerular capillary wall was determined using line-intercept methods on electron microscopic whole-glomerular montages (40). The filtration surface area (S) was then calculated as the product of filtration surface density and glomerular volume $\left(\mathrm{S}_{\mathrm{V}} \times \mathrm{V}_{\mathrm{G}}\right)$. Hydraulic permeability $(\mathrm{k})$ was assessed at an ultrastructural level $(\times 12,000)$ from a detailed evaluation of filtration slit frequency and thickness of the glomerular basement membrane (41). The $\mathrm{SNK}_{\mathrm{f}}$ was calculated as the product of the filtration surface area per glomerulus and the hydraulic permeability of the glomerular capillary wall $\left(\mathrm{SNK}_{\mathrm{f}}=\mathrm{S} \times \mathrm{k}\right)(41,42)$. The $\mathrm{N}_{\mathrm{FG}}$ was then calculated by dividing the $\mathrm{K}_{\mathrm{f}}$ by the $\mathrm{SNK}_{\mathrm{f}}\left(\mathrm{N}_{\mathrm{FG}}=\mathrm{K}_{\mathrm{f}} / \mathrm{SNK}_{\mathrm{f}}\right)$.

Estimation of glomerular number late post-donation. Since glomerular numbers cannot increase, any increase in the $\mathrm{K}_{\mathrm{f}}$ must be accounted for by a proportional glomerular hypertrophy-induced increase in the post-donation $\mathrm{SNK}_{\mathrm{f}}$. In order to calculate a conservative estimate of the late glomerular number, we assumed that maximal glomerular hypertrophy had occurred by early post-donation and that the $\Delta \mathrm{P}$ was constant at $40 \mathrm{mmHg}$. To estimate the early post-donation $\mathrm{SNK}_{\mathrm{f}}$ $\left(\mathrm{SNK}_{\mathrm{f} \text {-early }}\right)$, we used the following equation:

$$
\mathrm{SNK}_{\text {f-early }}=\frac{\mathrm{K}_{\text {f-early }}}{\mathrm{K}_{\mathrm{f} \text {-pre }}} \times \mathrm{SNK}_{\mathrm{f} \text {-pre }}
$$

(Equation 1) lows:

We then calculated the late post-donation $\mathrm{N}_{\mathrm{FG}}\left(\mathrm{N}_{\mathrm{FG}-\text { late }}\right)$ as fol-

$$
\mathrm{N}_{\mathrm{FG}-\text { late }}=\frac{\mathrm{K}_{\mathrm{f}-\text { late }}}{\mathrm{SNK}_{\text {t-early }}}
$$

(Equation 2)

Statistics. All results are reported as mean \pm SD or as median and interquartile range where distributions were Gaussian or non-Gaussian, respectively. Statistical analyses were performed using the 2-tailed Wilcoxon matched-pairs test, repeated measures ANOVA followed by Bonferroni's post-test, or Friedman's test followed by Dunn's post-test where appropriate. Correlation was assessed using Spearman's rankorder correlation. A $P$ value of less than 0.05 was considered significant.

Study approval. The study was approved by the IRB of Stanford University. Informed consent was obtained from all subjects prior to their participation in the study.

\section{Acknowledgments}

Funding was provided by grants from the NIH (R01DK064697); Astellas Pharma US; the John M. Sobrato Foundation; and the Satellite Extramural Grant Foundation. C.R. Lenihan receives support from an American Society of Nephrology (ASN) Research Fellowship. J.C. Tan receives support from the National Institute of Diabetes and Digestive and Kidney Diseases (K23DK087937). The Stanford Nephrology Fellowship program was supported by T32 DK007357. We acknowledge the contributions of Anjali Saxena, Bing Ho, Jieshi Yan, and Biruh Workeneh in the recruitment and retention of subjects in this longitudinal study.

Address correspondence to: Jane C. Tan, Division of Nephrology, Stanford University School of Medicine, 1070 Arastradero Road, Palo Alto, California 94304, USA. Phone: 650.725.4738; E-mail: janetan@stanford.edu.
1. Merrill JP, Murray JE, Harrison JH, Guild WR. Successful homotransplantation of the human kidney between identical twins. JAm Med Assoc. 1956;160(4):277-282.

2. Fehrman-Ekholm I, Elinder CG, Stenbeck M,
Tyden G, Groth CG. Kidney donors live longer Transplantation. 1997;64(7):976-978.

3. Ibrahim HN, et al. Long-term consequences of kidney donation. N Engl J Med. 2009;360(5):459-469.
4. Mjøen G, et al. Long-term risks for kidney donors. Kidney Int. 2014;86(1):162-167.

5. Muzaale AD, et al. Risk of end-stage renal disease following live kidney donation. JAMA. 2014;311(6):579-586. 
6. Krohn AG, Ogden DA, Holmes JH. Renal function in 29 healthy adults before and after nephrectomy. JAMA. 1966;196(4):322-324.

7. Saxena $A B$, et al. Adaptive hyperfiltration in the aging kidney after contralateral nephrectomy. Am JPhysiol Renal Physiol. 2006;291(3):F629-F634.

8. Deen WM, Robertson CR, Brenner BM. A model of glomerular ultrafiltration in the rat. Am JPhysiol. 1972;223(5):1178-1183.

9. Tan JC, Workeneh B, Busque S, Blouch K, Derby G, Myers BD. Glomerular function, structure, and number in renal allografts from older deceased donors. J Am Soc Nephrol. 2009;20(1):181-188.

10. Hostetter TH, Olson JL, Rennke HG, Venkatachalam MA, Brenner BM. Hyperfiltration in remnant nephrons: a potentially adverse response to renal ablation. Am J Physiol. 1981;241(1):F85-F93.

11. Anderson S, Meyer TW, Rennke HG, Brenner BM. Control of glomerular hypertension limits glomerular injury in rats with reduced renal mass. JClin Invest. 1985;76(2):612-619.

12. Brenner BM, Deen WM, Robertson CR. Determinants of glomerular filtration rate. Annu Rev Physiol. 1976;38:11-19.

13. Maddox DA, et al. Determinants of glomerular filtration in experimental glomerulonephritis in the rat. JClin Invest. 1975;55(2):305-318.

14. Brenner BM, Troy JL, Daugharty TM, Deen WM, Robertson CR. Dynamics of glomerular ultrafiltration in the rat. II. Plasma-flow dependence of GFR. Am J Physiol. 1972;223(5):1184-1190.

15. Blantz RC, Israelit AH, Rector FC, Seldin DW, Green JM. Relation of distal tubular $\mathrm{NaCl}$ delivery and glomerular hydrostatic pressure. Kidney Int. 1972;2(1):22-32.

16. Haylor J, Chowdry J, Baillie H, Cope G, el Nahas AM. Renal function and morphometry in the dwarf rat following a reduction in renal mass. Nephrol Dial Transplant. 1996;11(4):643-650.

17. Flyvbjerg A, et al. Compensatory renal growth in uninephrectomized adult mice is growth hormone dependent. Kidney Int. 1999;56(6):2048-2054.

18. Bhathena DB, Julian BA, McMorrow RG, Baehler RW. Focal sclerosis of hypertrophied glomeruli in solitary functioning kidneys of humans. $\mathrm{Am} \mathrm{J}$
Kidney Dis. 1985;5(5):226-232.

19. Kaplan C, Pasternack B, Shah H, Gallo G. Agerelated incidence of sclerotic glomeruli in human kidneys. Am J Pathol. 1975;80(2):227-234.

20. Kappel B, Olsen S. Cortical interstitial tissue and sclerosed glomeruli in the normal human kidney, related to age and sex. A quantitative study. Virchows Arch A Pathol Anat Histol. 1980;387(3):271-277.

21. Tan JC, et al. Effects of aging on glomerular function and number in living kidney donors. Kidney Int. 2010;78(7):686-692.

22. Nyengaard JR, Bendtsen TF. Glomerular number and size in relation to age, kidney weight, and body surface in normal man. Anat Rec. 1992;232(2):194-201.

23. Hoy WE, Douglas-Denton RN, Hughson MD, Cass A, Johnson K, Bertram JF. A stereological study of glomerular number and volume: preliminary findings in a multiracial study of kidneys at autopsy. Kidney Int Suppl. 2003;(83):S31-S37.

24. Garg AX, et al. Cardiovascular disease and hypertension risk in living kidney donors: an analysis of health administrative data in Ontario, Canada. Transplantation. 2008;86(3):399-406.

25. Wills AK, et al. Life course trajectories of systolic blood pressure using longitudinal data from eight UK cohorts. PLoS Med. 2011;8(6):e1000440.

26. Steiner RW, Tucker BJ, Blantz RC. Glomerular hemodynamics in rats with chronic sodium depletion. Effect of saralasin. JClin Invest. 1979;64(2):503-512.

27. Deen WM, Troy JL, Robertson CR, Brenner BM. Dynamics of glomerular ultrafiltration in the rat. IV. Determination of the ultrafiltration coefficient. J Clin Invest. 1973;52(6):1500-1508.

28. Blantz RC, Rector FC, Seldin DW. Effect of hyperoncotic albumin expansion upon glomerular ultrafiltration in the rat. Kidney Int. 1974;6(4):209-221.

29. Ott CE, Marchand GR, Diaz-Buxo JA, Knox FG. Determinants of glomerular filtration rate in the dog. Am J Physiol. 1976;231(1):235-239.

30. Thomas CE, Bell PD, Navar LG. Glomerular filtration dynamics in the dog during elevated plasma colloid osmotic pressure. Kidney Int. 1979;15(5):502-512.
31. Myers BD, et al. Role of cardiac atria in the human renal response to changing plasma volume. Am J Physiol. 1988;254(4 pt 2):F562-F573.

32. Loon N, Chagnac A, Parra L, Schmidt K, Deen WM, Myers BD. Filtration dynamics and natriuretic response to volume expansion in humans. Am J Physiol. 1992;263(2 pt 2):F284-F292.

33. Shemesh O, Deen WM, Brenner BM, McNeely E, Myers BD. Effect of colloid volume expansion on glomerular barrier size-selectivity in humans. Kidney Int. 1986;29(4):916-923.

34. Battilana C, Zhang HP, Olshen RA, Wexler L, Myers BD. PAH extraction and estimation of plasma flow in diseased human kidneys. Am J Physiol. 1991;261(4 pt 2):F726-F733.

35. Canaan-Kühl S, Venkatraman ES, Ernst SI, Olshen RA, Myers BD. Relationships among protein and albumin concentrations and oncotic pressure in nephrotic plasma. Am J Physiol. 1993;264(6 pt 2):F1052-F1059.

36. Dworkin LD, Hostetter TH, Rennke HG, Brenner BM. Hemodynamic basis for glomerular injury in rats with desoxycorticosterone-salt hypertension. J Clin Invest. 1984;73(5):1448-1461.

37. Steiner RW, Tucker BJ, Gushwa LC, Gifford J, Wilson CB, Blantz RC. Glomerular hemodynamics in moderate Goldblatt hypertension in the rat. Hypertension. 1982;4(1):51-57.

38. Christiansen T, Rasch R, Stødkilde-Jørgensen H, Flyvbjerg A. Relationship between MRI and morphometric kidney measurements in diabetic and non-diabetic rats. Kidney Int. 1997;51(1):50-56.

39. Sadowski EA, et al. Nephrogenic systemic fibrosis: risk factors and incidence estimation. Radiology. 2007;243(1):148-157.

40. Jensen EB, Gundersen HJ, Osterby R. Determination of membrane thickness distribution from orthogonal intercepts. J Microsc. 1979;115(1):19-33.

41. Drumond MC, Deen WM. Structural determinants of glomerular hydraulic permeability. Am J Physiol. 1994;266(1 pt 2):F1-F12.

42. Drumond MC, Kristal B, Myers BD, Deen WM. Structural basis for reduced glomerular filtration capacity in nephrotic humans. JClin Invest. 1994;94(3):1187-1195. 